\title{
RADIOGRAPHIC STUDY OF DENTALANOMALIES IN BRAZILIAN PATIENTS WITH NEUROPSYCHOMOTOR DISORDERS
}

\author{
Erick Nelo PEDREIRA ${ }^{1}$, Marina Cury Gallotini MAGALHÃES ${ }^{2}$, Camila Lopes CARDOSO³ \\ Luís Antônio de Assis TAVEIRA ${ }^{4}$, Cláudio Froes de FREITAS ${ }^{5}$
}

1- DDS, MSc, Graduate Student in Oral Pathology, Department of Stomatology, Bauru School of Dentisty, São Paulo State University, Bauru, SP, Brazil. Assistant Professor, Department of Pathologic Anatomy, Center for Health Sciences, Federal University of Pará, UFPa, Brazil.

2- DDS, MSc, PhD, Associate Professor, Department of Stomatology, Discipline of Oral Pathology, Dental School, University of São Paulo, São Paulo, SP, Brazil.

3- Undergraduate Student, Department of Stomatology, Bauru School of Dentisty, São Paulo State University, Bauru, SP, Brazil.

4- DDS, MSc, PhD, Associate Professor, Department of Stomatology, Bauru School of Dentisty, São Paulo State University, Bauru, SP, Brazil.

5- DDS, MSc, PhD, Associate Professor, Department of Stomatology,Dental School, University of São Paulo, São Paulo, SP, Brazil.

Correponding address: Camila Lopes Cardoso - Faculdade de Odontologia de Bauru, Departamento de Estomatologia, Disciplina de Cirurgia - Al. Octávio Pinheiro Brisolla No 9-75 - 17012901 - Bauru - São Paulo - Brasil - Phone: 551432358248 - Fax $55143235-8248$

e-mail: cardoso_lopes@yahoo.com.br; cardosolopes@usp.br

Received: April 24, 2007 - Accepted: July 5, 2007

\begin{abstract}
$T_{\text {he }}$

The purposes of this study were to investigate radiographically the dental and maxillomandibular in patients with neuropsychomotor disorders and determine the role of panoramic radiographs for quantitative and qualitative analyses of dental alterations. A total of 322 panoramic radiographs from 190 males and 132 females aged 4 to 57 years were obtained from the files of the Center for Care to Patients with Special Needs (CAPE; Dental School, University of São Paulo) and subdivided into syndromes, special needs, neurological, neuromuscular or cerebral disorders, and sequels of diseases. $32 \%$ of dental alterations were in tooth position, with $69 \%$ of this group associated with tooth rotation. The mandible accounted for $54.62 \%$ of alterations. The male gender (55.85\%) and the permanent dentition (78.7\%) were most affected. Panoramic radiographs were proved to be well suited for quantitative evaluation of dental anomalies of epidemiological nature. Panoramic radiographs are important diagnostic resources when applied to patients with special needs because of the difficulty to place intraoral films and held them correctly positioned during the radiographic technique.
\end{abstract}

Uniterms: Radiograph, panoramic; Maxillofacial complex; Neurological disorders; Patients with special needs.

\section{INTRODUCTION}

Several different extraoral radiographic techniques have been developed for establishment of diagnostic hypotheses with well established technical principles and precise indications, which have been complemented with recent methods of imaging diagnosis ${ }^{11}$.

The advantages of extraoral techniques are related to its simple operation and handling. The fact that the film is not introduced into the patient's mouth is an advantage to avoid the occurrence of gagging and improve the operation in patients with special needs, including significant reduction in the radiation dosage ${ }^{16}$.

Freitas, et al. ${ }^{8}$ emphasized the importance of radiographic examination in patients with special needs to investigate the tooth eruption pattern, root formation and development, topographic relationship of the roots with the maxillary sinus, analysis of the temporomandibular joint and identification of dental anomalies.

A previous study ${ }^{5}$ evaluated 2,379 panoramic radiographs of patients with special needs, including 1,500 males and 879 females aged 2 to 12 years. The methodology comprised clinical examination followed by panoramic radiograph. Congenital tooth absence was the most frequent dental alteration (3.7\%), followed by supernumerary teeth (0.46\%), fusion (0.42\%) and rotation (0.34\%). Another study ${ }^{2}$ analyzed 702 panoramic radiographs of children (328 males and 374 females) and observed anodontia in $8 \%$ of the sample. The mandibular second premolar and the lateral incisor were the most commonly missing teeth.

Early detection of dental alterations is of paramount importance for the adequate oral development of patients with neuropsychomotor disorders as well as for the establishment of the best treatment plan. Genetic alterations 
and ethnic differences have been described as key factors in the clinical and radiographic expression of the condition ${ }^{20}$.

This study analyzed radiographically the dental and maxillomandibular in patients with neuropsychomotor disorders in a closed population assisted at CAPE (Center for Care to Patients with Special Needs, Dental School, University of São Paulo) not comparing the results to those found in the general population. This study also attempted to determine the role of panoramic radiograph as an auxiliary diagnostic resource for quantitative and qualitative analyses of dental and maxillomandibular alterations.

\section{MATERIALAND METHODS}

The sample comprised 322 panoramic radiographs from 190 male and 132 female patients with neuropsychomotor disorders aged 4 years and 5 months to 57 years and 11 months. The panoramic radiographs belong to the files of the Center for Care to Patients with Special Needs (CAPE, Dental School, University of São Paulo) and were taken for diagnostic and treatment purposes. Patients considered as presenting neuropsychomotor disorders were subdivided in groups as displayed in Figure 1.

The panoramic radiographs were taken according to the principles of ellipsopantomography, using a Panex-E x-ray machine (J. Morita Corp., Osaka Japan) with 15-second exposure time. The panoramic films (Kodak TMG-RA1, size $15 \times 30 \mathrm{~cm}$ ) were placed in plastic and flexible cassettes with intensifying screens. The X-ray unit was set at $90 \mathrm{Kvp}$ and $10 \mathrm{~mA}$ and the films were automatically developed within 3 minute working time.

Radiographic interpretation was undertaken in a dark room with the aid of a view box, magnifying glass and dark card mask. Analyses were performed twice by two calibrated examiners (experienced radiologists) with a 60-day interval between the 1st and 2nd evaluations, to warrant the safety of data interpretation and reliability of the results.

The occurrence and frequency of the dental and maxillomandibular alterations described in Figure 2 were investigated.

The intra and inter-examiner agreement were evaluated by the Kappa statistics. Spearman's correlation coefficient was applied to evaluate the occurrence of alterations and dental and maxillomandibular anomalies in the following groups: syndromes, special needs, neurological disorders, neuromuscular disorders, sequels of diseases and others. Statistical analysis was performed using the GMC software version 7.4 (Pesquisa Biológica).

\section{RESULTS}

The results revealed a higher frequency of dental alterations in the mandible (54.62\%) and in the male gender (55.85\%). Most alterations occurred in individuals with specific syndromes and neurological disorders (Figure 3).

Anomalies in tooth position were the most prevalent

\begin{tabular}{|c|c|}
\hline \multirow{14}{*}{ 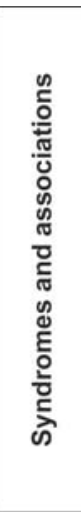 } & Angelman syndrome \\
\hline & Apert syndrome (acrocephalosyndactyly, acrodysplasia) \\
\hline & $\begin{array}{l}\text { Beals syndrome (congenital contractural arachnodactyly } \\
\text { syndrome) }\end{array}$ \\
\hline & Coffin-Siris syndrome \\
\hline & Down syndrome \\
\hline & Marfan syndrome \\
\hline & Maroteaux-Lamy syndrome (mucopolysaccharidosis IV) \\
\hline & Moebius syndrome (congenital facial diplegia) \\
\hline & Mohr syndrome (orofaciodigital syndrome type $\mathrm{VI}$ ) \\
\hline & Prader Labahart-Willi syndrome \\
\hline & Sturge Weber syndrome (encephalofacial angiomatosis) \\
\hline & Williams Beuren syndrome \\
\hline & Fragile X syndrome (Martin-Bell syndrome) \\
\hline & Crouzon disease (craniofacial dysostosis) \\
\hline \multirow{6}{*}{ 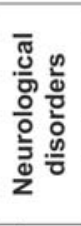 } & Autism \\
\hline & Convulsion \\
\hline & Epilepsy \\
\hline & Multiple sclerosis \\
\hline & Tuberous sclerosis \\
\hline & Mental retardation \\
\hline \multirow{3}{*}{ 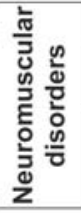 } & Muscular disturbance \\
\hline & $\begin{array}{l}\text { Duchenne muscular dystrophy (infantile progressive } \\
\text { muscular dystrophy) }\end{array}$ \\
\hline & Centro-nuclear congenital myopathy \\
\hline \multirow{5}{*}{ 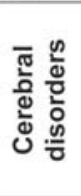 } & Neonatal anoxia \\
\hline & Arthrogriposis \\
\hline & Cerebral calcification \\
\hline & Microcephaly \\
\hline & Cerebral palsy \\
\hline \multirow{4}{*}{ 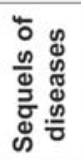 } & Congenital syphilis \\
\hline & Sequel of meningitis \\
\hline & Sequel of xeroderma pigmentosa \\
\hline & Sequel of rubella \\
\hline
\end{tabular}

FIGURE 1- Subdivision of the groups of patients with neuropsychomotor disorders

\begin{tabular}{|c|c|}
\hline \multirow{8}{*}{$\begin{array}{l}\text { Anomalies of } \\
\text { form }\end{array}$} & Macrodontia \\
\hline & Microdontia \\
\hline & Germination \\
\hline & Fusion \\
\hline & Amelogenesis imperfecta \\
\hline & Dentinogenesis imperfecta \\
\hline & Dens invaginatus \\
\hline & Taurodontism \\
\hline \multirow{5}{*}{ Root alteration } & Residual roots \\
\hline & Incompletely formed roots \\
\hline & Concrescence \\
\hline & Hypercementosis \\
\hline & Dilaceration \\
\hline \multirow{4}{*}{$\begin{array}{c}\text { Anomalies of } \\
\text { number }\end{array}$} & Total anodontia \\
\hline & Partial anodontia \\
\hline & Supernumerary teeth \\
\hline & Mesiodens \\
\hline \multirow{3}{*}{$\begin{array}{l}\text { Anomalies of } \\
\text { position }\end{array}$} & Migration \\
\hline & Transposition \\
\hline & Rotation \\
\hline \multirow{3}{*}{$\begin{array}{l}\text { Periapical } \\
\text { alteration }\end{array}$} & Circumscribed bone rarefaction \\
\hline & Diffuse bone rarefaction \\
\hline & Bone rarefaction (furcation lesion) \\
\hline \multirow{8}{*}{ Other } & Radiolucent bone lesions \\
\hline & Radiopaque bone lesions \\
\hline & Mixed bone lesions \\
\hline & Radiographic image suggestive of compound odontoma \\
\hline & Radiographic image suggestive of complex odontomas \\
\hline & Radiographic image suggestive of osteomyelitis \\
\hline & Radiographic image suggestive of cleft palate \\
\hline & Radiopacity in the maxillary sinus \\
\hline \multicolumn{2}{|c|}{ Morphological alteration of the TMJ } \\
\hline
\end{tabular}

FIGURE 2- Analysis of dental and maxillomandibular alterations 


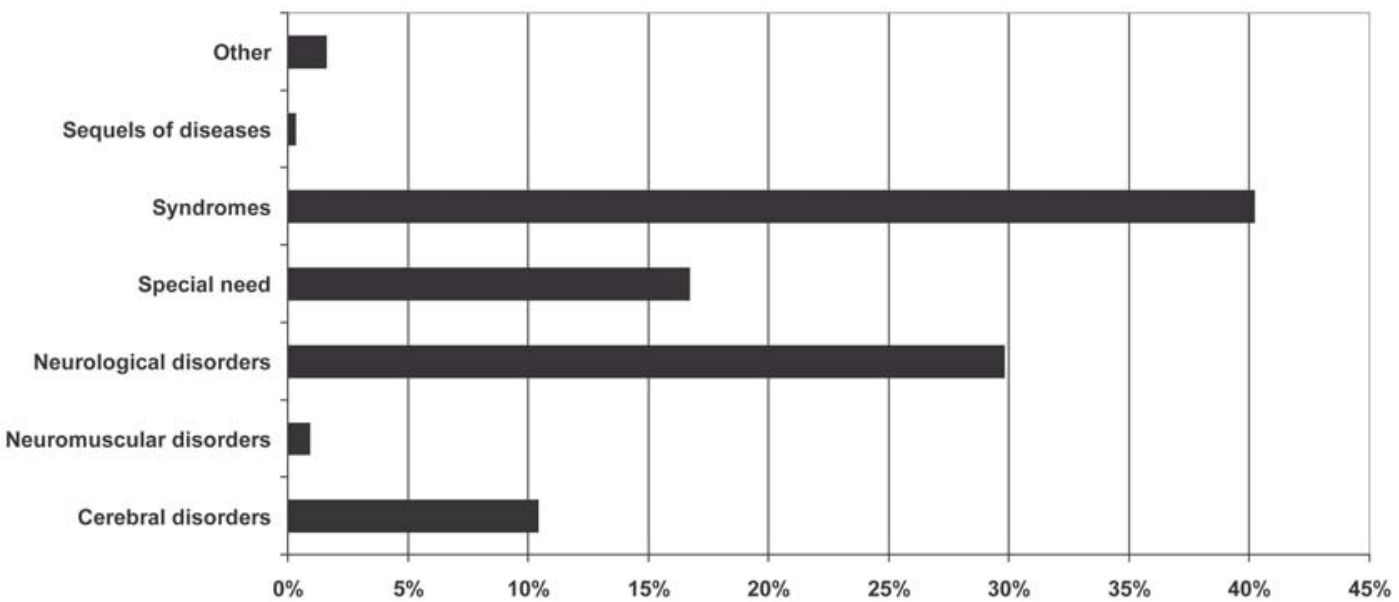

FIGURE 3- Histogram of dental and maxillomandibular alterations and anomalies for the different groups of neuropsychomotor disorders (in percentage)

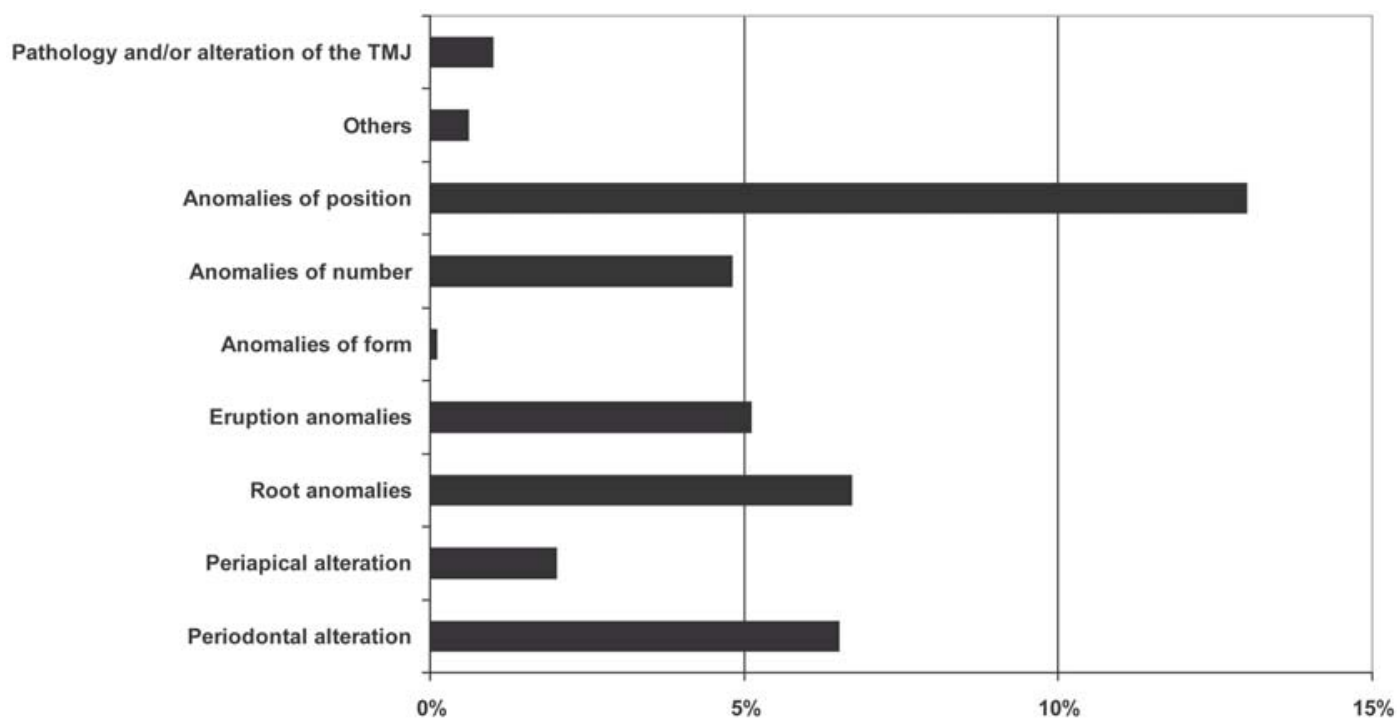

FIGURE 4- Histogram of the main dental and maxillomandibular alterations and anomalies on the evaluated panoramic radiographs

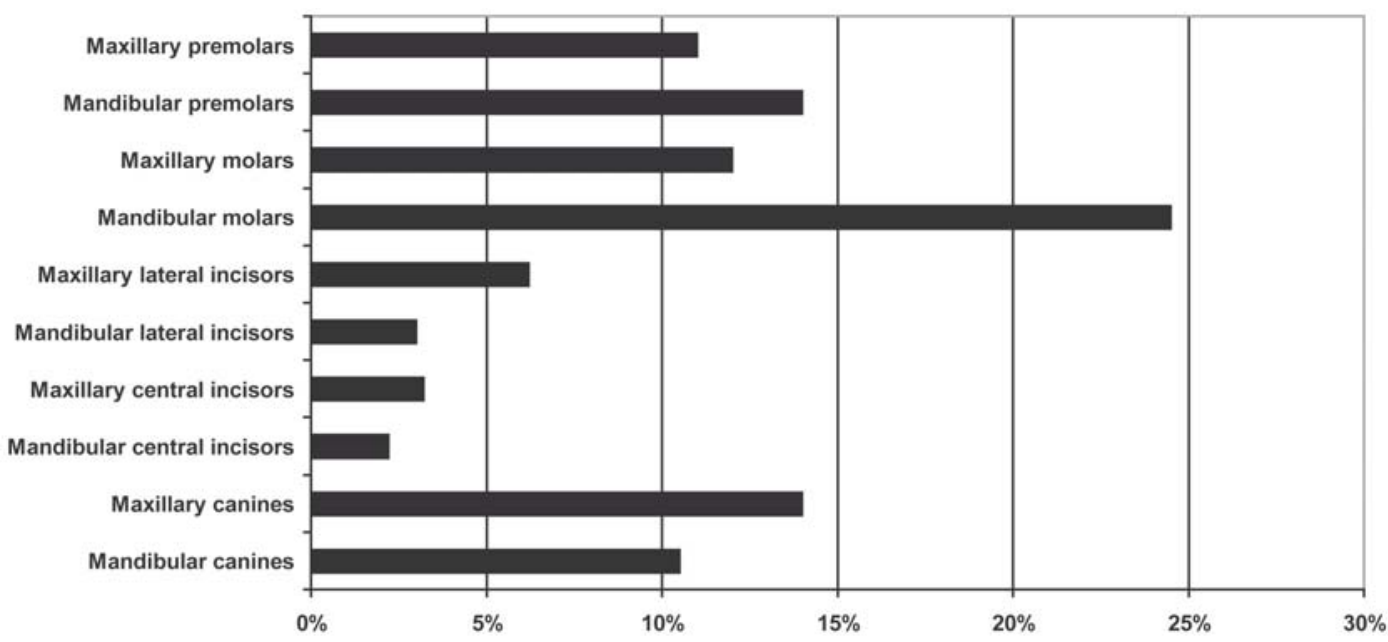

FIGURE 5- Histogram of the most affected groups of teeth in the permanent dentition 


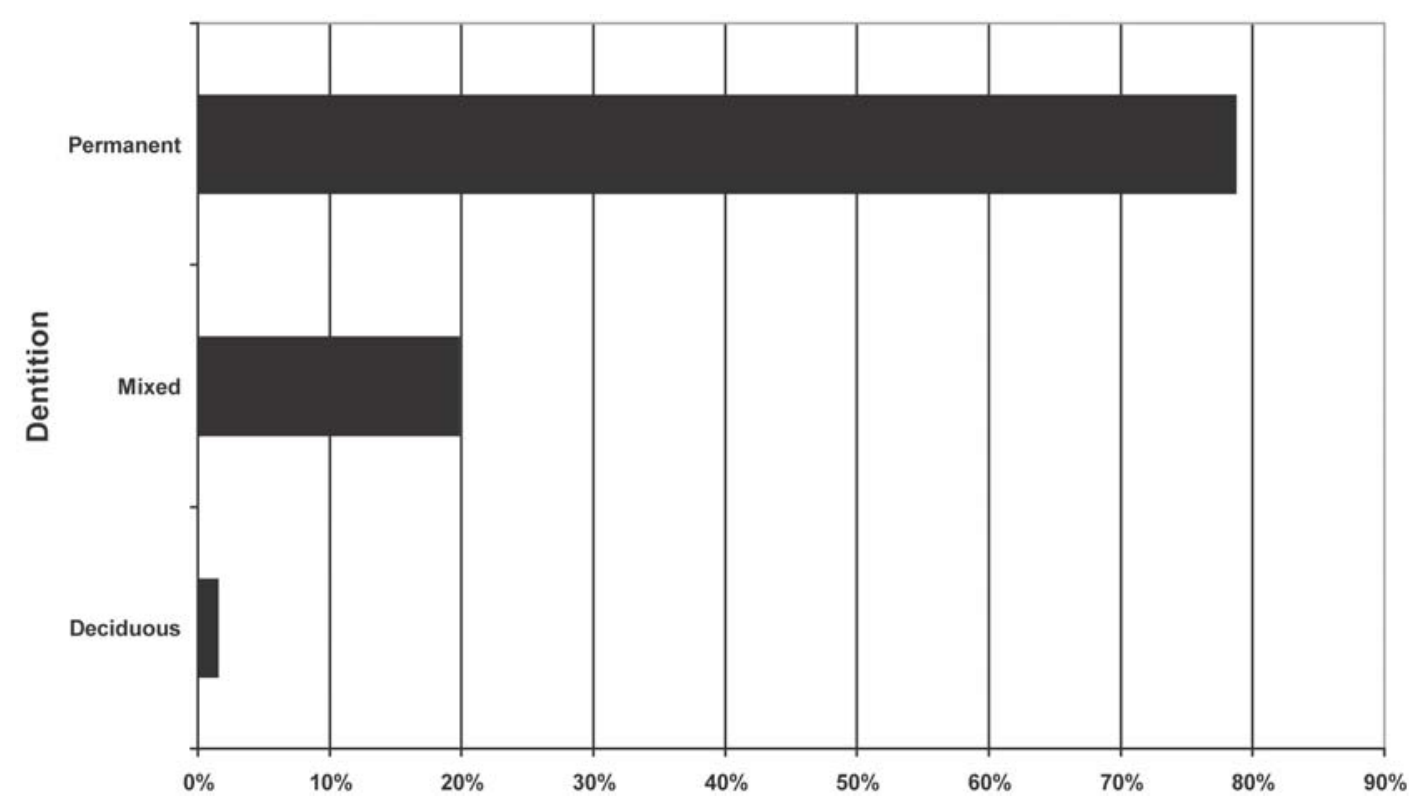

FIGURE 6- Histogram of the main dental and maxillomandibular alterations and anomalies for the three dentitions

(Figure 4). Canines, premolars and molars were the more frequently affected than incisors (Figure 5).

Figure 6 presents the dental and maxillomandibular alterations and anomalies for the deciduous, mixed and permanent dentitions. There was higher occurrence of anomalies in the permanent dentition (78.7\%).

\section{DISCUSSION}

Several studies have employed panoramic radiographs for analysis of images within the pattern of normality and identification of dental and maxillomandibular alterations ${ }^{3,10,15}$.

Genetic alterations and ethnic differences are key factors for the occurrence of dental alterations. The present sample comprised panoramic radiographs of individuals with psychomotor disorders, regardless of race, which included a large number of syndromes, associations and conditions, secondary to alterations in the genetic material ${ }^{15}$.

The results of this study revealed a higher frequency in the mandible and among males as to the occurrence of dental and maxillomandibular alterations and anomalies, which were better evidenced in the groups of syndromes, special needs and neurological disorders (Figure 3).

Reports of anodontia as the most frequent dental alteration $^{9,12}$ were not confirmed in the present study, in which rotation was the most frequent alteration. Maxillary lateral incisors and the mandibular second premolars were the most affected by alterations in a detailed epidemiologic radiographic study ${ }^{1}$. In the present study, however, dental anomalies most frequently occurred in the mandibular molars followed by mandibular premolars and maxillary canines.

Most citations related to anomalies of number were described by Fergusson et $\mathrm{al}^{7}$, Mass and Belostoky ${ }^{14}$, Bacetti $^{2}$ and Malmgren and Norgren ${ }^{13}$, who related the syndromes and associations to the occurrence of anodontia. The occurrence of supernumerary teeth has been associated with Prader-Labhart-Willi, Down and Marfan syndromes ${ }^{6,17,19}$.

Haavio, et al. ${ }^{9}$ have reported anomalies of position in individuals with mental retardation with $\mathrm{x}$-linked inheritance. In addition, the presence of rotation was very significant in this group of patients, corroborating the present outcomes.

Regarding the types of alterations in the three dentitions, there was predominance of anomalies of position, followed by anomalies of number in the deciduous and mixed dentitions. Tesini and Fanton ${ }^{18}$ and Bergman et $\mathrm{al}^{4}$ reported delayed eruption of permanent teeth, correlating tooth eruption with the chronological age of patients with neurological disorders, with aid of panoramic radiographs.

\section{CONCLUSION}

Anomalies of position, primarily represented by tooth rotation, were the most frequent alterations in the groups of patients of CAPE.

The permanent dentition was more affected than the mixed and deciduous dentitions.

Investigation of dental and maxillomandibular alterations in patients with neuropsychomotor disorders demonstrated that it is possible to use a conventional extraoral radiograph as a resource for qualitative observation associated with quantitative analysis of epidemiological nature. Use panoramic instead of intraoral radiographs is based on the difficulty of placement and maintenance of periapical and bitewing films in the correction position because special needs patients several involuntary movements. 


\section{ACKNOWLEDGMENTS}

We would like to thank CAPE - Center for Care to Patients with Special Needs, Dental School, University of São Paulo for granting access to the patients’ records and agreeing with the conduction of the study. We are thankful to engineer Marcelo Alves (ESALQ-USP) for his assistance with the statistical analysis, to Prof. Valdir Afonso for grammar correction and to the PICDT-CAPES program for funding.

\section{REFERENCES}

1- Acerbi AG, Freitas C, Magalhães MHG. Prevalence of numeric anomalies in the permanent dentition of patients with Down syndrome. Special Care Dentist. 2001;21(2):75-8.

2- Bacetti T. A clinical and statistical study of etiologic aspects related to associated tooth anomalies in number, size and position. Minerva Stomatol. 1998;12:655-63.

3- Benediktsdottir IS, Hintze H, Petersen JK, Wenzel A. Accuracy of digital and film panoramic radiographs for assessment of position and morphology of mandibular third molars and prevalence of dental anomalies and pathologies. Dentomaxillofac Radiol. 2003;32(2):10915.

4- Bergman A, Kjellberg H, Dahlgren J. Craniofacial morphology and dental age in children with Silver-Russel syndrome. Orthod Craniofac Res. 2003;6(1):2-19.

5- Buenviaje TM, Rapp R. Dental anomalies in children: a clinical and radiographic survey. J Dent Child. 1984;51(1):42-6.

6- Chew ST, Low TC. Preoperative versus postoperative pethidine for extraction of impacted third molar. Ann Acad Med Singapore. 1997;26(4):426-9.

7- Fergunson JW, Brown RH, Cheong LY. Pycnodisostosis associated with delayed and ectopic eruption of permanent teeth. Int J Paediatr Dent. 1991;1(1):35-41.

8- Freitas A, Torres FA. Radiografias panorâmicas. In: Rosa JE, Faria e Souza I. Radiologia Odontológica. 5 Ed. São Paulo: Artes Médicas; 2003. p.193-214.

9- Haavio ML. Oral health care of the mentally retarded and other persons with desabilities in the nordic countries: present situation and plans for the future. Spec Care Dentist. 1995;15(2):65-9.

10- Kumasaka S, Miyagi A, Sakai N, Shindo J, Kashima I. Oligodontia: a radiographic comparison of subjects with Down syndrome and normal subjects. Spec Care Dentist. 1997;17(4):137-41.

11- Langland OE, Sippy FH. Anatomic structures visualized on the panoramic radiograph. Oral Surg Oral Med Oral Pathol Oral Radiol. $1968 ; 26(4): 475-84$.

12- Lopez ME, Bazan C, Lorca IA, Chervonagura A. Oral and clinical characteristics of a group of patients with Turner syndrome. Oral Surg Oral Med Oral Pathol Oral Radiol. 2002;94(2):196-204.

13- Malmgren B, Norgren S. Dental aberrations in children and adolescents with osteogenesis imperfeita. Acta Odontol Scand. 2002;60(2):65-71.

14- Mass E, Belostoky L. Craniofacial morphology of children with Williams Syndrome. Cleft Palate Craniofac J. 1993;30(3):343-9.
15- Pilo R, Kaffe I, Amir E, Sarnat H. Diagnosis of developmental dental anomalies using panoramic radiographs. Dent Child. 1987;54(4):267-72.

16- Rushton VE, Horner K. Panoramic radiography. Br Dent J. 2003;194(1):11-4.

17-Saini T, Keene JJ, Whetten J. Radiographic diagnosis of supernumerary premolars: case reviews ASDC J Dent Child. 2002;69(2):184-90.

18- Tesini DA, Fenton SJ. Oral health needs of persons with physical or mental disabilities. Dent Clin North Amer. 1994;38(3):483-98.

19- Vasan N. Management of children with clefts of the lip or palate: an overview. N Z Dent J. 1999;95(419):14-20.

20- Waldman HB, Perlman SP. Dental care for individuals with developmental disabilities its expensive, but needed. J Calif Dent Assoc. 2002;30(6):427-32. 